\title{
Effect of temperature and heart rate variability on Phantom T1 maps
}

\author{
Vassilis Vassiliou ${ }^{1,2^{*}}$, Ee Ling Heng ${ }^{1,2}$, Evangelia Nyktari ${ }^{1}$, Andreas Greiser ${ }^{3}$, David Firmin ${ }^{1,2}$, Dudley J Pennell ${ }^{1,2}$, \\ Peter Gatehouse ${ }^{1,2}$, Sanjay K Prasad ${ }^{1,2}$ \\ From 18th Annual SCMR Scientific Sessions \\ Nice, France. 4-7 February 2015
}

\section{Background}

Phantoms are increasingly being used for quality assurance when undertaking T1 mapping for myocardial interstitial fibrosis to ensure long-term stability of methods applied in patients e.g. against scanner alterations, across multi scanners and multi centers. We sought to investigate whether temperature and heart rate (HR) variability could influence Phantom T1/ECV as such a variation will need to be considered in the quality assurance process.

\section{Methods}

$\mathrm{NiCl}_{2}$-agarose gel phantoms [1] prepared in a standardised lab following a reproducible procedure as previously reported [2]. For the HR variability 4 phantoms were used to model native and post-contrast T1 of blood and myocardium; They were imaged with a prototype 11 HB MOLLI 5(3)3 (Siemens prototype WIP448B) at low resolution $(\mathrm{HR}>90 \mathrm{bpm})$ and high resolution (<90bpm) for RR 1400-490ms representing HR 43-122 bpm (Avanto, Siemens, 1.5T) at steady temperature. For the temperature variability 4 phantoms were prepared to mimic short and long $\mathrm{T} 1$ at $25^{\circ} \mathrm{C}$ (Phantom $\mathrm{B} 1=1915 \mathrm{~ms}$, $\mathrm{B} 2=1040 \mathrm{~ms}, \mathrm{~B} 3=530 \mathrm{~ms}, \mathrm{~B} 4=280 \mathrm{~ms})$. A water bath was prepared where were the phantoms were immersed, starting from a temperature of $35{ }^{\circ} \mathrm{C}$ cooling down to $15^{\circ} \mathrm{C}$.

\section{Results}

Heart rate variability

There was a small but definite increase in ECV with increase in HR as shown in fig 1a. This followed a linear relationship $(\mathrm{ECV}=0.013 \times$ heart rate $+27.4, \mathrm{R} 2=0.85)$ suggesting an increase in ECV of $0.13 \%$ for every increase in $10 \mathrm{bpm}$. For quality assurance it supports that HR should be indexed across vendors and sites. This difference is unlikely to be relevant for patients unless imaged in decompensated states (e.g. uncontrolled heart failure, fast atrial fibrillation). However, this change in ECV appears to be driven predominantly by a change in native blood $\mathrm{T} 1$ (Native blood $\mathrm{T} 1=-0.78 \mathrm{X}$ $\mathrm{HR}+1700, \mathrm{R} 2=0.90$ ) as shown in (fig $1 \mathrm{~b}$ ). Hence, in patients with extreme heart rates, it would appear that native myocardial $\mathrm{T} 1 \mathrm{might}$ be more accurate as this does not show variability with changes in HR (T1 native myocardium $=0.017 \times \mathrm{HR}+981, \mathrm{R} 2=0.02)$.

\section{Temperature}

With increase in temperature the T1 of Phantoms B1 and B2 appeared to increase $(\mathrm{B} 1 \mathrm{~T} 1=23.86 \times \mathrm{Temp}+1323$, $\mathrm{R} 2=0.99$ and $\mathrm{B} 2 \mathrm{~T} 1=6.27 \times \mathrm{Temp}+883, \mathrm{R} 2=0.98)$. The shorter T1 phantoms (B3 and B4) did not show an association with temperature changes, in accordance with previously published work from 1987 on $\mathrm{Ni}^{2+}$ doped phantoms [1].

\section{Conclusions}

Heart rate variability has been shown to have a small but definite effect on the T1 values and ECV. Temperature variability can also affect the longer $\mathrm{T} 1$ values. Therefore, for successful T1 quality assurance with phantoms, both temperature and heart rate should be standardised. Such changes could further have implications for patients and new research is required to address this.

${ }^{1}$ CMR, Royal Brompton Hospital, London, UK

Full list of author information is available at the end of the article 


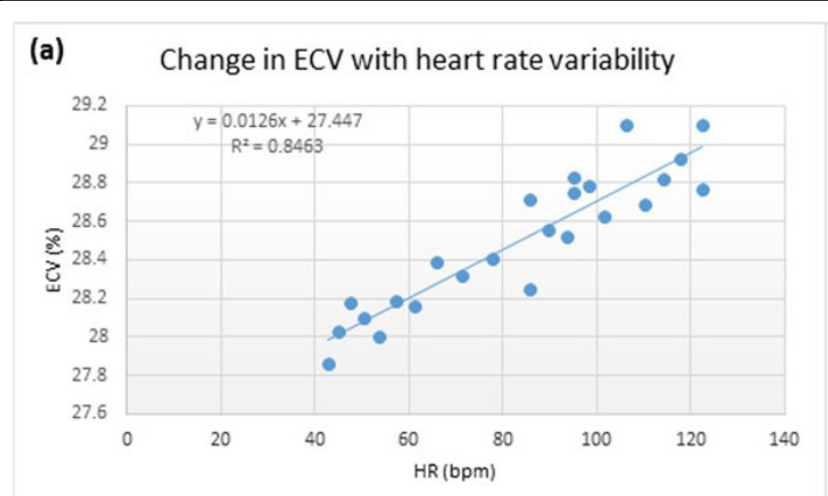

(b) T1 map change with heart rate variability

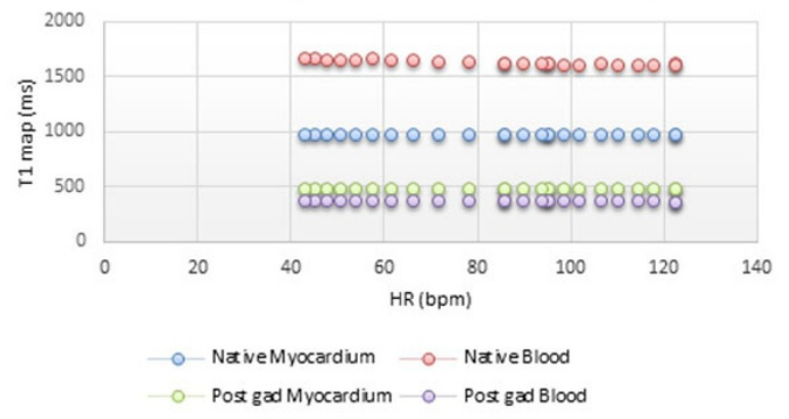

(c) T1 change with temperature variability

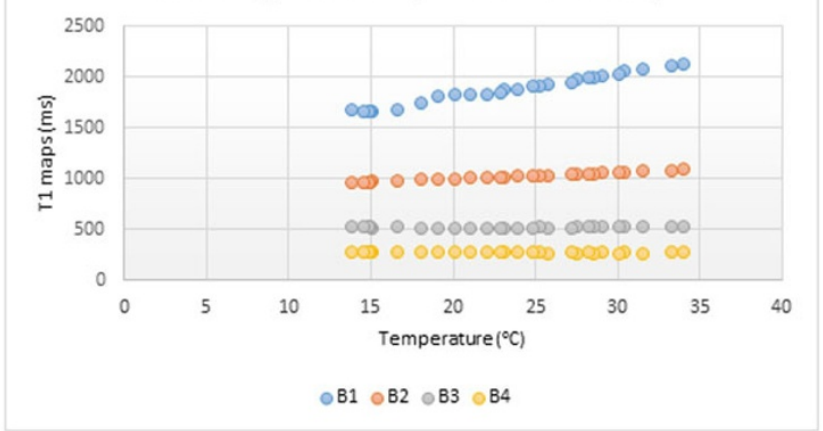

Figure 1 a) demosntrating a small but linear relationship between ECV and heart rate variability. b) shows that the native blood T1 are most affected. c) showing changes in T1 values with temperature variability. No ECV values were calculated as the T1 values did not mimic "human values".

\section{Funding}

NIHR Cardiovascular Biomedical Research Unit of Royal Brompton \& Harefield NHS Foundation Trust and Imperial College London.

\section{Authors' details}

${ }^{1}$ CMR, Royal Brompton Hospital, London, UK. ${ }^{2}$ National Heart and Lung

Institute, Imperial College London, London, UK. ${ }^{3}$ Siemens, Germany,

Germany.

Published: 3 February 2015

\section{References}

1. Kraft, et al: MRM 1987.

2. Heng, et al: JCMR 2014

doi:10.1186/1532-429X-17-S1-W24

Cite this article as: Vassiliou et al.: Effect of temperature and heart rate variability on Phantom T1 maps. Journal of Cardiovascular Magnetic Resonance 2015 17(Suppl 1):W24

\section{Submit your next manuscript to BioMed Central} and take full advantage of:

- Convenient online submission

- Thorough peer review

- No space constraints or color figure charges

- Immediate publication on acceptance

- Inclusion in PubMed, CAS, Scopus and Google Scholar

- Research which is freely available for redistribution

Submit your manuscript at www.biomedcentral.com/submit 